\title{
A!
}

This is an electronic reprint of the original article.

This reprint may differ from the original in pagination and typographic detail.

Tuomisto, Filip

\section{Defects in nitrides, positron annihilation spectroscopy}

\section{Published in:}

Gallium Nitride Materials and Devices VIII

DOI:

$10.1117 / 12.2000251$

Published: 01/01/2013

Document Version

Publisher's PDF, also known as Version of record

Please cite the original version:

Tuomisto, F. (2013). Defects in nitrides, positron annihilation spectroscopy. In J-I. Chyi, Y. Nanishi, H. Morkoc, J. Piprek, E. Yoon, \& H. Fujioka (Eds.), Gallium Nitride Materials and Devices VIII (pp. 1-10). [86250G]

(Proceedings of SPIE; Vol. 8625). https://doi.org/10.1117/12.2000251

This material is protected by copyright and other intellectual property rights, and duplication or sale of all or part of any of the repository collections is not permitted, except that material may be duplicated by you for your research use or educational purposes in electronic or print form. You must obtain permission for any other use. Electronic or print copies may not be offered, whether for sale or otherwise to anyone who is not an authorised user. 


\section{Defects in nitrides, positron annihilation spectroscopy}

Filip Tuomisto

Filip Tuomisto, "Defects in nitrides, positron annihilation spectroscopy," Proc. SPIE 8625, Gallium Nitride Materials and Devices VIII, 86250G (22 February 2013); doi: $10.1117 / 12.2000251$

SPIE. Event: SPIE OPTO, 2013, San Francisco, California, United States 


\title{
Defects in nitrides, positron annihilation spectroscopy
}

\author{
Filip Tuomisto \\ Department of Applied Physics, Aalto University, POB 11100, 00076 Aalto, Finland
}

\begin{abstract}
In-grown group III (cation) vacancies $\left(\mathrm{V}_{\mathrm{Ga}}, \mathrm{V}_{\mathrm{Al}}, \mathrm{V}_{\mathrm{In}}\right)$ in $\mathrm{GaN}$, AlN and InN tend to be complexed with donor-type defects These donor defects may in principle be residual impurities such as $\mathrm{O}$ or $\mathrm{H}, n$-type dopants such as $\mathrm{Si}$, or intrinsic defects such as the $\mathrm{N}$ vacancy $\left(\mathrm{V}_{\mathrm{N}}\right)$. The cation vacancies and their complexes are generally deep acceptors, and hence they compensate for the $n$-type conductivity and add to the scattering centers limiting the carrier mobility in these materials. $\mathrm{Mg}$ doping reduces the group III vacancy concentrations, but other kinds of vacancy defects emerge. This work presents results obtained with positron annihilation spectroscopy in GaN, AlN, and InN. The vacancy-donor complexes are different in these three materials, and their importance in determining the opto-electronic properties of the material varies as well. The formation of these defects is discussed in the light of the differences in the growth methods.
\end{abstract}

Keywords: GaN, AlN, InN, positron, vacancy, defect

\section{INTRODUCTION}

The material family of the III-nitrides has a wide range of existing and potential applications in optoelectronics, with active wavelengths ranging from infrared to ultraviolet (UV). Extended defects in III-nitride substrates, especially threading dislocations, have been studied extensively over the years with the aim of finding optimal growth conditions that would minimize their density and optimize device characteristics. Also point defects influence the electrical and optical characteristics of the materials and devices. In addition, they can have a role in the formation of the extended defects, for example by acting as initiating centers for inversion layers and dislocations.

A variety of techniques can be applied to identify defects in semiconductors on the atomic scale. The main advantage of positron annihilation spectroscopy is in its ability to selectively detect vacancy-type defects. The positron has two special properties that give this asset: it has a positive charge and it annihilates with electrons. The sensitivity of positrons to vacancy-type defects is rather easy to understand. A free positron in a crystal lattice feels strong repulsion from the positive ion cores, and an open-volume defect like a vacant lattice site is hence an attractive center where the positron gets trapped. The reduced electron density at the vacant site increases the positron lifetime, while the missing valence and core electrons cause substantial changes in the momentum distribution of the annihilating electrons. Two positron techniques have been efficiently used in defect studies in semiconductors, namely the positron lifetime and the Doppler broadening of the $511 \mathrm{keV}$ line. These methods, accompanied by state-of-the-art theoretical calculations, provide a straightforward tool for the identification of vacancy-type defects. A significant advantage of positron annihilation spectroscopy is that it can be applied both to bulk crystals and thin layers of any electrical conduction type. Performing measurements as a function of temperature gives information on the charge states of the detected defects.

The dominant form of existence of in-grown group III (cation) vacancies $\left(\mathrm{V}_{\mathrm{Ga}}, \mathrm{V}_{\mathrm{Al}}, \mathrm{V}_{\mathrm{In}}\right)$ in $\mathrm{GaN}$, AlN and InN is a complex with a donor-type defect ${ }^{1-3}$, typically on the $\mathrm{N}$ sublattice. This donor defect may in principle be a residual impurity such as $\mathrm{O}$ or $\mathrm{H}$, an $n$-type dopant such as $\mathrm{Si}$, or an intrinsic defect such as the $\mathrm{N}$ vacancy $\left(\mathrm{V}_{\mathrm{N}}\right)$. The cation vacancies and their complexes are generally deep acceptors, and hence they compensate for the $n$-type conductivity and add to the scattering centers limiting the carrier mobility in these materials. They have also been shown to contribute to sub-bandgap optical absorption and deep level luminescence, such as the parasitic yellow luminescence in $\mathrm{GaN}^{4}$ and $\mathrm{UV}$ absorption in $\mathrm{AlN}^{2}$.

We present results obtained in a variety of $\mathrm{GaN}, \mathrm{AlN}$ and $\mathrm{InN}$ materials grown by different methods. The identification of the vacancies and vacancy complexes is based on comparison with irradiated samples where isolated vacancy defects can be observed, while in as-grown materials only vacancy complexes are detected. State-of-the art theoretical calculations $^{3,5}$ provide significant support for the identification through modelling of the relevant positron annihilation parameters. Interestingly, the vacancy-donor complexes are different in $\mathrm{GaN}$, AlN and $\mathrm{InN}$, and their importance in 
determining the opto-electronic properties of the material varies as well. In $\mathrm{GaN}$ and $\mathrm{AlN}$ the $\mathrm{V}_{\mathrm{III}}-\mathrm{O}_{\mathrm{N}}$ complex is the dominant in-grown acceptor-type vacancy ${ }^{1,2}$, while in $\mathrm{InN}$ it seems to be the $\mathrm{V}_{\mathrm{In}}-\mathrm{V}_{\mathrm{N}}$ divacancy, irrespective of the doping (whether by residual $\mathrm{O}$ or intentional $\mathrm{Si}$ ) ${ }^{3}$. Interestingly, in $n$-type $\mathrm{GaN}$ the $\mathrm{V}_{\mathrm{Ga}}-\mathrm{O}_{\mathrm{N}}$ complexes are the dominant compensating centers ${ }^{1}$, in $n$-type $\mathrm{InN}$ the $\mathrm{V}_{\mathrm{In}}-\mathrm{V}_{\mathrm{N}}$ complexes are co-dominant with (so far unidentified) negative iontype defects ${ }^{6,7}$, while in AlN the cation vacancy complexes provide at most $10 \%$ of the compensating effect ${ }^{2,8}$. The formation of these defects is discussed in the light of the differences in the growth methods of the III-nitrides. Doping with $\mathrm{Mg}$ in order to make p-type material typically reduces the group III vacancy concentrations, as expected from thermodynamics, but often other kinds of vacancy defects are created instead. $\mathrm{N}$ vacancies complexed with $\mathrm{Mg}$ and clusters of vacancies have been observed ${ }^{9,10}$.

\section{METHODS}

\subsection{III-nitride materials}

Positron annihilation results have been obtained on a large variety of III-nitride materials grown by different techniques. During the past decade, samples grown by various groups by molecular beam epitaxy (MBE) $)^{11-16}$, metal-organic chemical vapor deposition (MOCVD) ${ }^{17-19}$, hydride vapor phase epitaxy (HVPE) ${ }^{20-22}$, the high nitrogen pressure method $(\mathrm{HNP})^{23}$, physical vapor transport (PVT) ${ }^{24,25}$, and the ammonothermal method (AT) $)^{26}$ have been studied. These growth techniques have important differences among others in the chemical environment, pressure, and growth temperature, resulting in very different growth modes and rates and residual impurity (most important are $\mathrm{O}$ and $\mathrm{H}$ ) concentrations. In addition, the possibilities of doping the material with, e.g., $\mathrm{Mg}$ or $\mathrm{Si}$, vary strongly between the different growth methods.

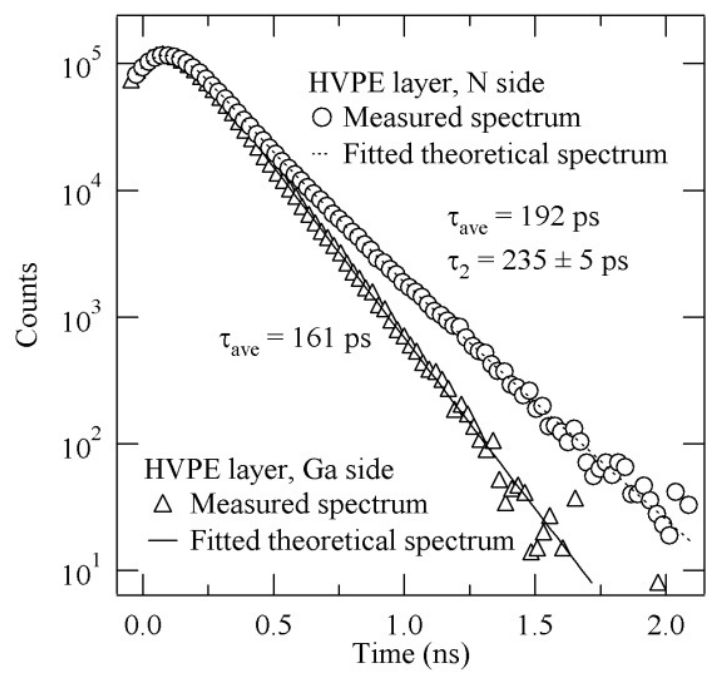

Figure 1: Examples of positron lifetime spectra in HVPE GaN samples A constant background and annihilations in the source materials have been subtracted from the spectra, which consist of $2 \times 10^{6}$ recorded annihilation events. The solid lines are fits of the sum of exponential components convoluted with the resolution function of the spectrometer. The data were recorded at $300 \mathrm{~K}$.

\subsection{Positron annihilation spectroscopy}

The positron lifetimes in bulk crystals (hundreds of micrometers thick samples) can be measured with a conventional fast-fast coincidence spectrometer with a time resolution of $250 \mathrm{ps}^{27}$. Two identical sample pieces are sandwiched with a $20 \mu \mathrm{Ci}$ positron source $\left({ }^{22} \mathrm{Na}\right.$ deposited on $1.5 \mu \mathrm{m} \mathrm{Al}$ foil). Typically $2 \times 10^{6}$ annihilation events are collected in each positron lifetime spectrum. The positron lifetimes in thin film samples are studied with a pulsed positron beam ${ }^{6,28}$. The lifetime spectrum $n(t)=\tau_{i} I_{i} \exp \left(-t / \tau_{i}\right)$ is analyzed as the sum of exponential decay components (see Fig. 1) convoluted with the Gaussian resolution function of the spectrometer, after subtracting the constant background and annihilations in the source material (typically a few percent, for details see $e$.g. Ref. 4) The positron in state $i$ annihilates with a lifetime $\tau_{i}$ and an intensity $I_{i}$. The state in question can be the delocalized state in the lattice or the localized state at a vacancy 
defect. The increase of the average lifetime $\tau_{\text {ave }}=\Sigma_{i} I_{i} \tau_{i}$ above the bulk lattice lifetime $\tau_{B}$ shows that vacancy defects are present in the material. This parameter is insensitive to the decomposition procedure, and even as small a change as $1 \mathrm{ps}$ in its value can be reliably measured. In the case of one type of vacancy defect with specific lifetime $\tau_{V}$, the decomposition of the lifetime spectrum into two components $\tau_{1}$ and $\tau_{2}$ is straightforward to interpret. The second lifetime component $\tau_{2}=\tau_{V}$ gives directly the vacancy specific lifetime and the first lifetime component is $\tau_{1}=\left(\tau_{B}{ }^{-1}+\kappa_{V}\right)^{-1}<\tau_{B}$, where $\tau_{B}$ is the positron lifetime in the delocalized state in the lattice and $\tau_{\mathrm{V}}$ the positron trapping rate into the vacancy defects.

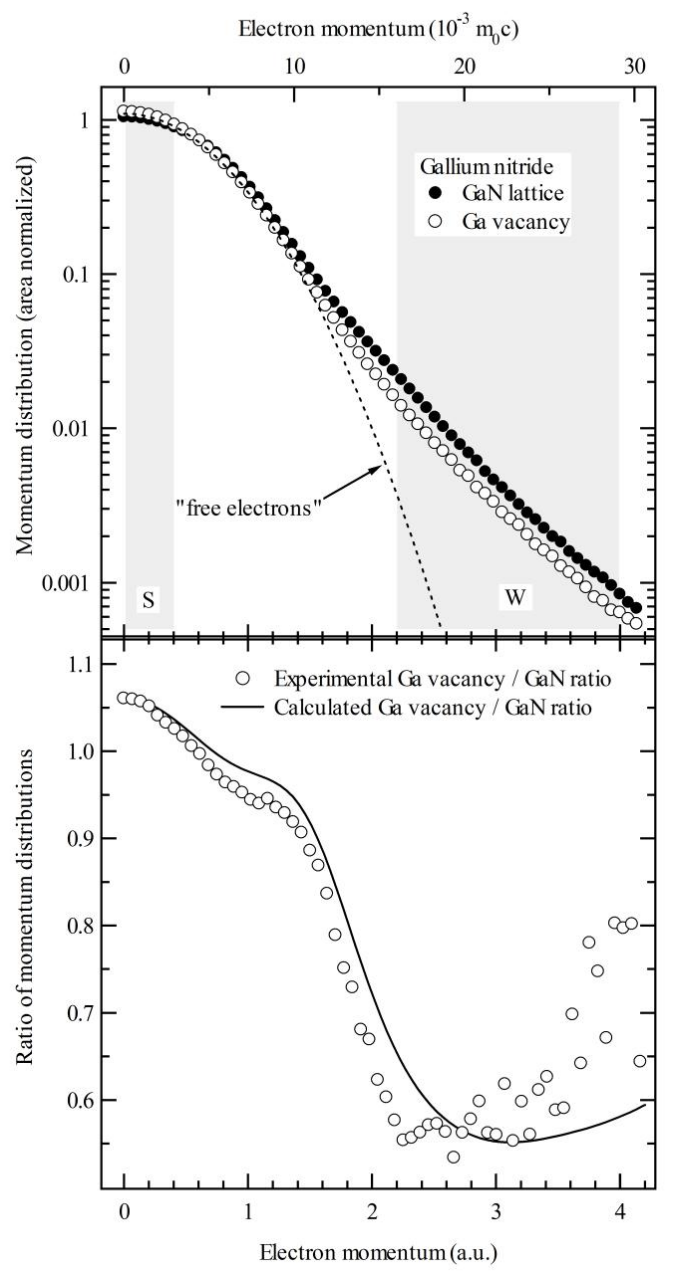

Fig. 2: Typical folded Doppler broadening spectra obtained with two HPGe detectors in coincidence (upper panel). The integration windows for $\mathrm{S}$ and $\mathrm{W}$ parameters are shown. The lower panel shows the so-called ratio curve obtained by normalizing the vacancy-specific data to that of the lattice. From Ref. [29] with permission.

The temperature dependence of the average positron lifetime $\tau_{\text {ave }}$ is analyzed with the model of trapping and escape rates of positrons, explained in detail in earlier works ${ }^{4,30}$. In this model, the trapping coefficient $\kappa_{V}$ to a neutral vacancy is independent of temperature and to a negatively charged vacancy it varies as $T^{-0.5}$. The trapping rate of positrons into the vacancies (concentration $\left.c_{V}\right)$ is $\kappa_{V}=\mu_{V} c_{V}\left(\mu_{V}=3 \times 10^{15} \mathrm{~cm}^{3} \mathrm{~s}^{-1}\right.$ for Ga vacancies in GaN at $300 \mathrm{~K}$ ). Positrons can get trapped also at hydrogen-like Rydberg states surrounding negative-ion-type defects (shallow traps for positrons). The positron trapping rate at the Rydberg state $\mu_{R}$ varies also as $T^{-0.5}$, which is the result predicted by theory for the transition from a free state to a bound state in a Coulomb potential ${ }^{31}$. 
The Doppler broadening experiments in thin films are performed using a variable-energy (0.5-38 keV) slow positron beam. The Doppler broadening of the e-p annihilation radiation is recorded with two Ge-detectors with a combined Gaussian resolution function of $1.24 \mathrm{keV}(0.66$ a.u.) and $0.995 \mathrm{keV}(0.53$ a.u.) full-width-at-half-maximum (FWHM) at $0.511 \mathrm{MeV}$ in the conventional and coincidence Doppler setup ${ }^{3,27}$, respectively. In the latter configuration, both annihilation photons are detected simultaneously and only counted if energy conservation is fulfilled $\left(E_{\text {tot }}=1.022 \mathrm{MeV}\right)$. This significantly improves the peak-to-background ratio up to $10^{6}$ and sharpens the detector resolution. To ensure statistical reliability, spectra of $\sim 1 \times 10^{6}$ and $\sim 3 \times 10^{7}$ counts are accumulated for each measurement point in the conventional and coincidence setup, respectively. In conventional Doppler mode the annihilation peak is analyzed using the common integrated lineshape parameters ${ }^{3,27}$ which represent the annihilation fractions in the low (S) and high (W) momentum parts of the spectrum. Integration windows of $\left|p_{L}(\mathrm{~S})\right|<0.4$ a.u. $\left(\Delta E_{g}<0.75 \mathrm{keV}\right)$ and 1.5 a.u. $<\left|p_{L}(\mathrm{~W})\right|<3.9$ a.u. (2.9 keV $\left.<\Delta E_{g}<7.3 \mathrm{keV}\right)$ are chosen for the $\mathrm{S}$ and $\mathrm{W}$ parameter, respectively. The identification of defect states from positron annihilation data (lifetimes, Doppler broadening) is supported by state-of-the-art theoretical calculations, see Refs. 3 and 5 for details on the applied methods (see also Fig. 2).

A few practical notes (for a detailed presentation, see, e.g., Ref. 27) are in place in order to obtain a rough understanding of positron annihilation data: the positrons act as a local probe of the electronic structure. The trapping of positrons into vacancies and ensuing annihilation results in an increase of the positron lifetime compared to the so-called bulk lifetime (lifetime in perfect lattice) due to the reduction of the total electron density at the vacancy that leads to a reduced annihilation rate. On the other hand, the interaction of the positrons with high-momentum core electrons is reduced when the positrons are localized in vacancies, resulting in the first approximation in a narrowing of the Doppler broadened annihilation peak (higher S, lower W).

\section{IDENTIFICATION OF VACANCY DEFECTS}

\subsection{Ga and $\mathrm{N}$ vacancies in $\mathrm{GaN}$}

The positron lifetime in the defect-free $\mathrm{GaN}$ lattice has been measured to be about $160 \mathrm{ps}^{4,30}$, and in a sample with low enough vacancy defect concentration the positron lifetime spectrum contains only one exponential, see Fig. 1. After 2$\mathrm{MeV}$ electron irradiation at room temperature a longer (second) lifetime component $\tau_{2}=235 \pm 10 \mathrm{ps}$ is detected in the measured spectrum, a similar effect is seen in samples rich in oxygen impurities ${ }^{1,30}$. The longer lifetime component can be directly associated to Ga vacancies based on the comparison to theoretical calculations that predict a difference of 70 ps between the Ga vacancy and the bulk lifetimes, when lattice relaxations around the vacancy are taken into account ${ }^{1}$. On the other hand, the positron lifetime in the $\mathrm{N}$ vacancy, even with a strong outward relaxation, would be at most 20 25 ps longer than in the bulk ${ }^{1}$. In order to put the identification on an even firmer basis, the Doppler broadening results obtained in the irradiated GaN samples can be compared with the theoretical ones. The experimental data for the Ga vacancy can be extracted from the Doppler broadening spectrum with the help of the annihilation fractions obtained from the lifetime measurements ${ }^{1,30}$. The lower panel of Figure 2 represents both the experimentally determined and theoretically calculated ratios of the $\mathrm{V}_{\mathrm{Ga}}$-specific momentum distribution to that of the GaN lattice. The agreement between the theoretically ( $a b$ initio) calculated and experimentally determined ratio curves is excellent ${ }^{1}$.

The ratio curve in Fig. 2 has specific features that can be followed when results are compared (between experiment and theory and between different defects). The ratio curve for the $\mathrm{V}_{\mathrm{Ga}}$ exhibits a distinct line shape with a maximum of $\sim 1.06$ at the peak center region ( 0 a.u.). For momenta above 0.6 a.u. the ratio drops below 1 and an articulate shoulder is visible at $1.2-1.3$ a.u.. This shoulder can be analyzed in more detail by performing calculations with the superposition of atomic orbitals scheme (ATSUP) that shows that in this momentum range the most important contribution to the spectrum originates from $\mathrm{N} 2 \mathrm{p}$ electrons ${ }^{3}$. The strong reduction (down to values of about $\sim 0.55$ ) in intensity above momenta of 2.0 a.u. comes from a reduced overlap with Ga $3 \mathrm{~d}$ electrons when positrons are localized at a Ga vacancy (nearest neighbors are all $\mathrm{N}$ atoms).

The role of the negatively charged Ga vacancies in $\mathrm{GaN}$ is rather clear: they are deep acceptors that compensate for the n-type conductivity, albeit not very efficiently in as-grown material. On the other hand, the properties of the $\mathrm{N}$ vacancies are still very much under debate (see Ref. [32] and the references therein). The main reason for the lack of understanding of this defect is that it is very difficult to detect experimentally, due to either the small size of the $\mathrm{N}$ vacancy, or too high concentrations of other defects, or special requirements for charge states, depending on the experimental method. It is generally accepted that the $\mathrm{N}$ vacancy has donor character. 
Even though the small size of the $\mathrm{N}$ vacancy is problematic for positrons, some evidence of its detection has been obtained in a few positron experiments ${ }^{9,30}$. Mg-doped GaN grown by MOCVD is an example of a material where $\mathrm{N}$ vacancies have been observed wtih positrons as complexes with substitutional $\mathrm{Mg}$ acceptors ${ }^{9}$. In that work, the $\mathrm{V}_{\mathrm{N}}-\mathrm{Mg}$ complexes were associated with a lifetime component of $\tau_{\mathrm{V}}=180 \pm 5 \mathrm{ps}$, and were found to disappear together with the activation of the $\mathrm{Mg}$ acceptors in thermal annealings. Another example is high-purity GaN grown by HVPE and irradiated with $0.45 \mathrm{MeV}$ electrons, whose energy is too low to produce damage on the Ga sublattice ${ }^{30}$. Nevertheless, vacancy defects with $\tau_{\mathrm{V}}=190 \pm 10 \mathrm{ps}$ were found in the irradiated samples, and these defects disappeared after thermal treatments at around $300^{\circ} \mathrm{C}$, together with the removal of $\mathrm{N}$ vacancy-attributed photoluminescence features ${ }^{32}$. Also here the simplest interpretation was that these vacancy defects are $\mathrm{V}_{\mathrm{N}}$. However, more work is required to conclusively identify the $\mathrm{N}$ vacancy characteristics in positron experiments.

\subsection{Al vacancy defects in AIN}

The identification of Al-vacancy related defects in AlN is based on experiments in PVT grown bulk AlN crystals before and after $9.5 \mathrm{MeV}$ proton irradiation ${ }^{2}$. Both the as-grown and irradiated material give a single positron lifetime at and below room temperature, being 155 - 157 ps (not shown here), and this has been interpreted as the bulk lifetime in AlN. At temperatures well above room temperature, the lifetime results for the as-grown and irradiated AIN differ slightly, as the irradiation produces additional vacancies, but in both the second lifetime component that can be separated from the lifetime spectra is $\tau_{\mathrm{V}}=210 \pm 5 \mathrm{ps}$, and is interpreted as originating from Al vacancy related defects.

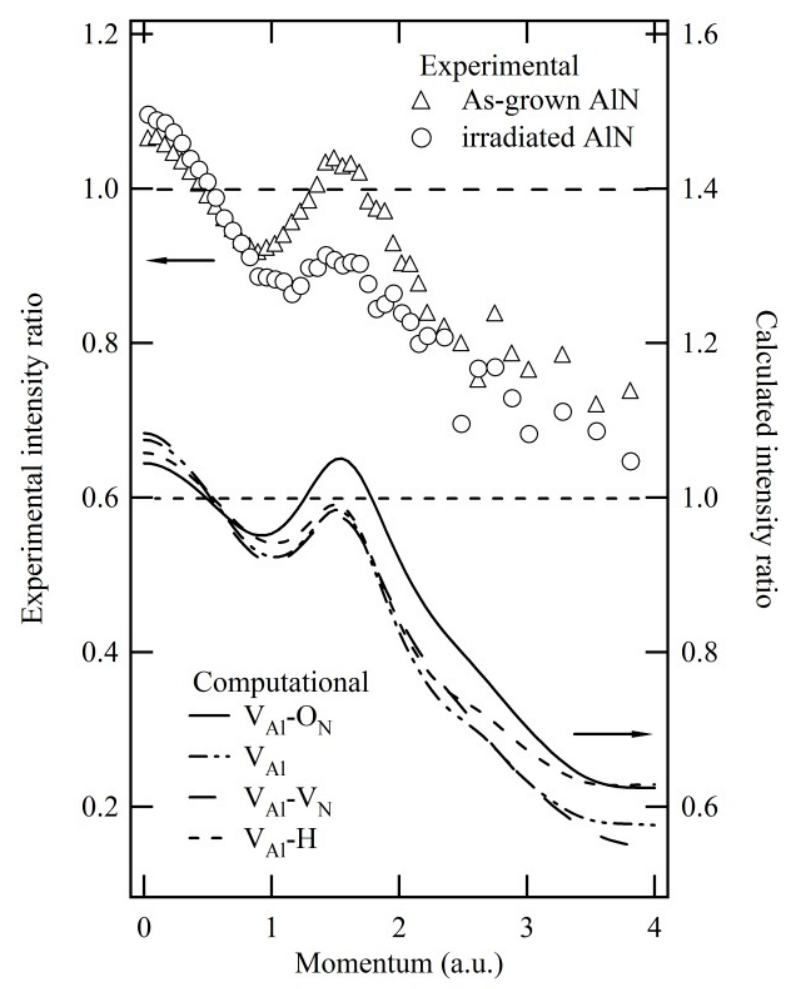

Fig. 3: Experimental (upper panel) and theoretical (lower panel) coincidence intensity ratios for $\mathrm{V}_{\mathrm{Al}}$ and $\mathrm{V}_{\mathrm{Al}}-\mathrm{O}_{\mathrm{N}}$ relative to defect free AlN. Theoretical calculations for $\mathrm{V}_{\mathrm{Al}}-\mathrm{V}_{\mathrm{N}}$ and $\mathrm{V}_{\mathrm{Al}}-\mathrm{H}$ are shown for comparison. From Ref. [2] with permission.

Coincidence Doppler measurements were performed in order to obtain direct evidence of the chemical surroundings of the Al vacancy found in the lifetime experiments. Based on the lifetime experiments, the annihilation fractions of positrons at $\mathrm{Al}$ vacancies in the as-grown and irradiated samples can be determined and used to extract the vacancyspecific Doppler spectrum $\rho_{\mathrm{V}}$ through $\rho_{\text {meas }}=\left(1-\eta_{\mathrm{V}}\right) \rho_{\mathrm{B}}+\eta_{\mathrm{V}} \rho_{\mathrm{V}}$, where $\rho_{\text {meas }}$ is the measured spectrum and $\rho_{\mathrm{B}}$ that specific of the AlN lattice. Figure 3 shows the experimental coincidence Doppler spectra as a ratio to the spectrum of the AlN lattice. The figure also shows theoretical calculations for the isolated $\mathrm{V}_{\mathrm{Al}}, \mathrm{V}_{\mathrm{A}} \mathrm{l}-\mathrm{O}_{\mathrm{N}}, \mathrm{V}_{\mathrm{Al}}-\mathrm{V}_{\mathrm{N}}$ and $\mathrm{V}_{\mathrm{Al}}-\mathrm{H}$. Clearly the 
experimental curve of the as-grown sample is in the best agreement with $\mathrm{V}_{\mathrm{Al}}-\mathrm{O}_{\mathrm{N}}$. Especially the shoulder with intensity $>1$ around 1.5 a.u. is unique to $\mathrm{O}$ decoration of the $\mathrm{Al}$ vacancy. It should be noted that this is a typical effect of $\mathrm{O}$ in III nitrides in general: A similar shoulder of increased intensity is seen in $\mathrm{GaN}^{1}$ and $\mathrm{InN}^{3}$ - the contribution of $2 \mathrm{p}$ electrons is important in this part of the spectrum. Also, the slightly higher intensity at higher momenta (2-4 a.u.) and lower intensity at zero momentum fits perfectly with $\mathrm{V}_{\mathrm{Al}}-\mathrm{O}_{\mathrm{N}}$ in the as-grown sample. Adding more $\mathrm{O}$ atoms increases the height of the shoulder even more (not shown for clarity), suggesting that there is only a single $\mathrm{O}$ atom neighboring the $\mathrm{Al}$ vacancy. In the irradiated sample, the possibility that part of the Al vacancies are decorated by $\mathrm{V}_{\mathrm{N}}$ (i.e., $\mathrm{V}_{\mathrm{Al}^{-}}-\mathrm{V}_{\mathrm{N}}$ complexes) cannot be ruled out. In any case, the Doppler spectrum is dominated by the irradiation-induced $V_{\mathrm{Al}}$. In addition, the Doppler spectrum is dominated by $\mathrm{V}_{\mathrm{Al}}-\mathrm{O}_{\mathrm{N}}$ in the as-grown material, indicating that this is the dominant form of in-grown $\mathrm{V}_{\mathrm{Al}}$.
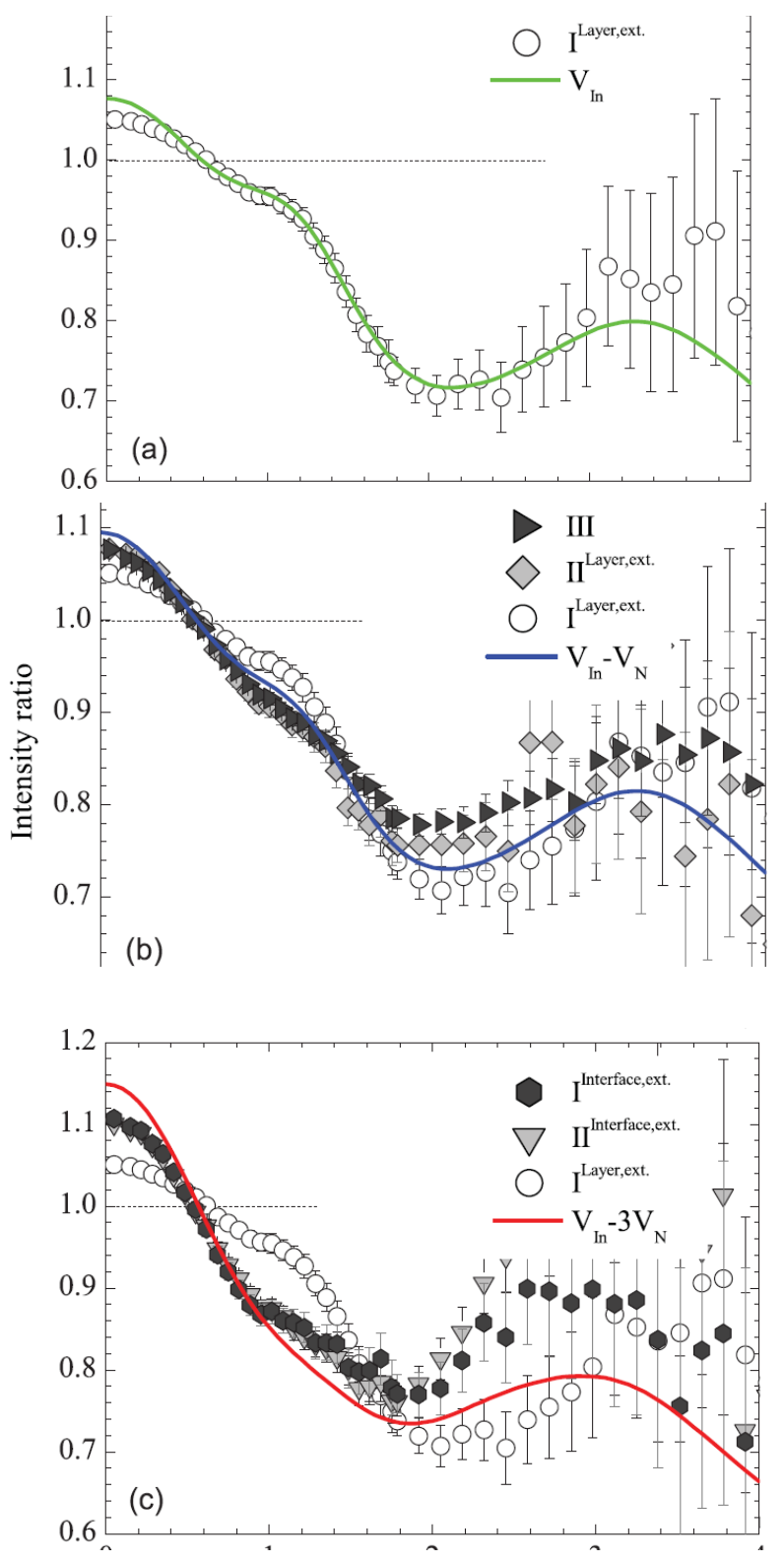

Fig. 4: Experimental coincidence Doppler spectra of the investigated samples in the layer (a), (b) and interface (c) region. The data has been divided by a suitable reference spectrum for the InN lattice. Computational ratio curves are shown for comparison. From Ref. [3] with permission. 


\subsection{Vacancy complexes in InN}

Positron lifetime experiments are much more complicated to perform in $\mathrm{InN}$, as bulk crystals of high crystalline quality do not exist. Only thin films with fairly high dislocation densities have been studied, and a pulsed positron beam has been used in order to obtain lifetime data. Both earlier ${ }^{33}$ and recent ${ }^{34}$ results suggest, however, that the bulk positron lifetime in InN is $\tau_{\mathrm{B}} \approx 180 \mathrm{ps}$. In addition, in the more recent work ${ }^{34}$ a vacancy lifetime of $\tau_{\mathrm{V}} \approx 260$ ps was found and attributed to In vacancy related defects. Interestingly, even though the Doppler broadening parameters are typically observed to evolve as a function of the distance from the layer-substrate interface in both MOCVD and MBE grown material $^{3,6,7,35,36}$, the lifetime values are constant throughout the layers ${ }^{33,34}$. This indicates that the nature of the vacancy defects varies within the layers without affecting the vacancy lifetime, and that the concentration of the vacancy defects does not change within the layers.

In order to identify the vacancy defects in the various InN samples and the origin of the above-described behavior, an extensive study on 2-MeV He irradiated ${ }^{38,39}$ (sample type I), MBE-grown ${ }^{37}$ (sample type II) and MOCVD-grown ${ }^{35}$ (sample type III) material was performed ${ }^{3}$. Figure 4 shows the coincidence Doppler broadening spectra for all these kinds of samples. The data are shown as ratio curves, and they have been extrapolated using the annihilation fractions obtained from lifetime experiments. From the experimental data, it is evident that the vacancy defects have different character in different samples and as a function of whether the data were taken from the bulk of the thin layer of from the near-interface region. Importantly, by comparison to theoretical calculations, the In vacancy defects produced in the irradiation are isolated as expected. On the in-grown In vacancy defects are always complexed with $1-3 \mathrm{~N}$ vacancies, with the number of the $\mathrm{V}_{\mathrm{N}}$ decorating the $\mathrm{V}_{\mathrm{In}}$ increasing towards the layer-substrate interface. The changes in (gradual removal of) the shoulder at around 1.2 a.u. are characteristic to the removal of $\mathrm{N}$ atoms next to $\mathrm{V}_{\mathrm{In}}$. For comparison, the theoretical calculations for, e.g., $\mathrm{V}_{\text {In }}-\mathrm{O}_{\mathrm{N}}$ and $\mathrm{V}_{\text {In }{ }^{-} \mathrm{H}}$ complexes have similar character as for the other nitrides (not shown here): $\mathrm{O}$ increases the intensity of the same shoulder, while $\mathrm{H}$ has very little effect and predominantly in the highmomentum part (above 2 a.u.).

\section{DISCUSSION}

The advanced combination of experimental positron lifetime and Doppler broadening spectroscopies with state-of-the-art theoretical calculations have allowed the identification of the complexes as either $\mathrm{V}_{\mathrm{Ga} / \mathrm{Al}}-\mathrm{O}_{\mathrm{N}}$ in $\mathrm{GaN}^{1}$ and $\mathrm{AlN}^{2}$ or $\mathrm{V}_{\mathrm{In}}-$ $\mathrm{V}_{\mathrm{N}}$ in $\mathrm{InN}^{3}$. In addition, the concentrations of these vacancy defects can be estimated from the data when they are in the range $10^{15}-10^{19} \mathrm{~cm}^{-3}$. The results obtained in the various III-nitride materials in this respect, together with the typical impurity concentrations, have been reviewd in Ref. 40.

In GaN the in-grown vacancy related defects have been shown to be the dominant intrinsic acceptor defects in $n$-type $\mathrm{GaN}$ when impurities (such as $\mathrm{Mg}$ ) acting as acceptors are not present ${ }^{1}$. This conclusion has been confirmed by the very good match of vacancy and total acceptor densities, obtained by combining positron annihilation and temperaturedependent Hall measurements ${ }^{20}$. Thermal annealing experiments of as-grown and electron-irradiated GaN have confirmed the theoretical predictions for the formation energy of the isolated Ga vacancy ( $E^{f} \approx 1.5 \mathrm{eV}$ in strongly $n$-type material) and the binding energy of the $\mathrm{V}_{\mathrm{Ga}}-\mathrm{O}_{\mathrm{N}}$ pair $\left(E_{B}=1.6 \mathrm{eV}\right) \cdot{ }^{30,41}$ Further, studying the differences in Ga vacancy distributions in $\mathrm{GaN}$ grown in the Ga- and N-polar directions as well as in non-polar directions, both in homo- and hetero-epitaxial HVPE samples, has given more detailed information on the formation of $\mathrm{V}_{\mathrm{Ga}}-\mathrm{O}_{\mathrm{N}}$ complexes $\mathrm{s}^{20,22,42,43,44}$. The Ga vacancies are created thermally as isolated at the high growth temperatures such as HVPE and HNP GaN, but their ability to form $\mathrm{V}_{\mathrm{Ga}}-\mathrm{O}_{\mathrm{N}}$ complexes determines the fraction of vacancy defects surviving the cooling down. The $\mathrm{O}$ incorporation from the growth ambient and the subsequent vacancy formation (at high temperature) depends on the growth polarity due to the different sticking of $\mathrm{O}$ on different growth surfaces. Interestingly, this picture of vacancy formation does not, however, seem to be valid when $\mathrm{GaN}$ is grown by methods that use lower temperatures, such as MBE or AT. The vacancy concentrations found in these materials strongly exceed what could be expected by thermodynamical considerations ${ }^{40}$. The same can be stated for InN that is always grown at relatively low temperatures ${ }^{6,733,36,37,45-47}$. The comparison is more difficult in AlN, as theoretical predictions give rather low values for the formation energy ${ }^{48}$ of $\mathrm{V}_{\mathrm{Al}}$, making the expected vacancy concentrations quite high. In addition, the growth temperature of AlN is always relatively high, making thermal formation of point defects favorable.

It is important to note that in $\mathrm{GaN}$ the $\mathrm{O}$ content does indeed strongly affect the vacancy concentration, and also in AlN the main form of existence of the cation vacancies is as a complex with oxygen ${ }^{2,49,50}$. On the other hand, in InN the $\mathrm{O}$ 
content can vary from $10^{17}$ to $10^{20} \mathrm{~cm}^{-3}$ (for one growth method) without having any effect on the observed vacancy concentrations. The role of hydrogen is more difficult to assess, as it is usually present at relatively high (but rather constant) concentrations. Recent results suggest, however, that Ga vacancy - hydrogen complexes may be important defects in MOCVD GaN ${ }^{51}$. It is generally thought that high extended defect concentrations go hand in hand with high vacancy concentrations. In III-nitrides this seems to hold for high-temperature techniques, but this does not seem to be the case for low-temperature techniques ${ }^{40}$.

Cation vacancies in III-nitrides are generally believed to introduce deep levels in the band gap of the material, and this is supported by theoretical calculations ${ }^{48,52}$. Partly as a consequence, the Ga vacancies and their complexes have been linked to the parasitic yellow luminescence exhibited by many GaN samples. Indeed, in experiments these two (and also $\mathrm{C}$ impurities) are often found to coexist and the luminescence intensity to correlate with defect concentrations ${ }^{4,53,54}$. Recent theoretical calculations are in favor of both the $\mathrm{Ga}$ vacancies and $\mathrm{C}$ impurities contributing to the yellow luminescence ${ }^{55}$. Interestingly, no evidence has been presented on Ga vacancy related defects causing absorption in the visible range - even relatively thick samples with rather high Ga vacancy concentrations are colorless. Recent experiments suggest, on the other hand, that Ga vacancies and their complexes with hydrogen are an important source of non-radiative recombination in $\mathrm{GaN}^{51}$. The absorption experiments performed on AlN samples where different kinds of vacancies have been found ${ }^{2}$ suggest that both the isolated and oxygen-decorated $\mathrm{Al}$ vacancies cause important subbandgap absorption in AlN in the near-ultraviolet range. There are no reports linking optical properties of InN with its vacancy defects. It should be noted that although the cation vacancies are important acceptor-type compensating defects in n-.type material in all the III-nitrides, their concentrations are typically much lower than those of the n-type dopants. Hence the compensation they provide and their effects on the mobility tend to remain secondary compared to positively charged defects and dislocations (the densities of the latter are still rather high in AlN and $\mathrm{InN}$ ).

\section{SUMMARY}

Positron annihilation spectroscopy can be used to identify and quantify vacancy defects in semiconductors - in IIInitrides in particular the cation vacancies and their complexes. In-grown metal vacancies in GaN, AlN and InN are typically complexed with a donor-type impurity such as $\mathrm{O}, \mathrm{H}$ or $\mathrm{Si}$, or an intrinsic donor-type defect such as the $\mathrm{N}$ vacancy. The cation vacancies and their complexes are generally deep acceptors generating both radiative and nonradiative deep levels in the gap and limit the carrier mobility in these materials. They are formed during material synthesis and device processing steps. Interestingly, the vacancy-donor complexes are different in GaN, AlN and InN, and their importance in determining the opto-electronic properties of the material varies as well.

\section{REFERENCES}

[1] Hautakangas, S., Ranki, V., Makkonen, I., Puska, M. J., Saarinen, K., Xu, X., and Look, D. C., Phys. Rev. B 73, 193301 (2006).

[2] Mäki, J.-M., Makkonen, I., Tuomisto, F., Karjalainen, A., Suihkonen, S., Räisänen, J., Chemekova, T. Yu., and Makarov, Yu. N., Phys. Rev. B 84, 081204(R) (2011).

[3] Rauch, C., Makkonen, I., and Tuomisto, F., Phys. Rev. B 84, 125201 (2011).

[4] Saarinen, K., Laine, T., Kuisma, S., Nissilä, J., Hautojärvi, P., Dobrzynski, L., Baranowski, J. M., Pakula, K., Stepniewski, R., Wojdak, M., Wysmolek, A., Suski, T., Leszczynski, M., Grzegory, I., and Porowski, S., Phys. Rev. Lett. 79, 3030 (1997).

[5] Makkonen, I., Hakala, M., and Puska, M. J., Phys. Rev. B 73, 035103 (2006).

[6] Rauch, C., Tuomisto, F., King, P. D. C., Veal, T. D., Lu, H., Schaff, W. J., Appl. Phys. Lett. 101, 011903 (2012).

[7] Rauch, C., Tuomisto, F., Vilalta-Clemente, A., Lacroix, B., Ruterana, P., Kraeusel, S., Hourahine, B., and Schaff., W. J., Appl. Phys. Lett. 100, 091907 (2012).

[8] Tuomisto, F., Mäki, J.-M., Chemekova, T. Yu., Makarov, Yu. N., Avdeev, O. V., Mokhov, E. N., Segal, A. S., Ramm, M. G., Davis, S., Huminic, G., Helava, H., Bickermann, M., and Epelbaum, B. M., J. Crystal Growth 310, 3998 (2008).

[9] Hautakangas, S., Oila, J., Alatalo, M., Saarinen, K., Liszkay, L., Seghier, D., Gislason, H. P., Phys. Rev. Lett. 90, 137402 (2003).

[10] Tuomisto, F., Mäki, J.-M., and Zajac, M., J. Crystal Growth 312, 2620-2623 (2010). 
[11] Ptak, A. J., Holbert, L. J., Ting, L., Swartz, C. H., Moldovan, M., Giles, N. C., Myers, T. H., Van Lierde, P., Tian, C., Hockett, R. A., Mitha, S., Wickenden, A. E., Koleske, D. D., and Henry, R. L., Appl. Phys. Lett. 79, 2740 (2001).

[12] Lu, H., Schaff, W. J., Hwang, J., Wu, H., Yeo, W., Pharkya, A., and Eastman, L., Appl. Phys. Lett. 77, 2548 (2000).

[13] Gallinat, C. S., Koblmüller, G., Brown, J. S., Bernardis, S., Speck, J. S., Chern, G. D., Readinger, E. D., Shen, H., and Wraback, M., Appl. Phys. Lett. 89, 032109 (2006).

[14] Gallinat, C. S., Koblmüller, G., and Speck, J. S., Appl. Phys. Lett. 95, 022103 (2009).

[15] Koblmüller, G., Gallinat, C. S., Bernardis, S., Speck, J. S., Chern, G. D., Readinger, E. D., Shen, H., and Wraback, M., Appl. Phys. Lett. 89, 071902 (2006).

[16] Koblmüller, G., Reurings, F., Tuomisto, F., and Speck, J. S., Appl. Phys. Lett. 97, 191915 (2010).

[17] Dadgar, A., Krost, A., Christen, J., Bastek, B., Bertram, F., Krtschil, A., Hempel, T., Bläsing, J., Haboeck, U., and Hoffmann, A., J. Crystal Growth 297, 306 (2006).

[18] Ruffenach, S., Moret, M., Briot, O., and Gil, B., Phys. Status Solidi A 207, 9 (2010).

[19] Suihkonen, S., Sormunen, J., Rangel-Kuoppa, V.-T., Koskenvaara, H., and Sopanen, M., J. Crystal Growth 291, 8 (2006).

[20] Oila, J., Kivioja, J., Ranki, V., Saarinen, K., Look, D. C., Molnar, R. J., Park, S. S., Lee, S. K., and Han, J. Y., Appl. Phys. Lett. 82, 3433 (2003).

[21] Gogova, D., Siche, D., Fornari, R., Monemar, B., Gibart, P., Dobos, L., Pecz, B., Tuomisto, F., Bayazitov, R., and Zollo, G., Semicond. Sci. Techn. 21, 702 (2006).

[22] Tuomisto, F., Paskova, T., Kröger, R., Figge, S., Hommel, D., Monemar, B., and Kersting, R., Appl. Phys. Lett. 90, 121915 (2007).

[23] Grzegory, I., Krukowski, S., Leszczynski, M., Perlin, P., Suski, T., and Porowski, S., Acta Phys. Pol. A 100, Suppl. 57 (2001).

[24] Bickermann, M., Epelbaum, B. M., and Winnacker, A., J. Crystal Growth 269, 432 (2004).

[25] Mokhov, E. N., Avdeev, O. V., Barash, I. S., Chemekova, T. Yu., Roenkov, A. D., Segal, A. S., Wolfson, A. A., Makarov, Yu. N., Ramm, M. G., and Helava, H., J. Crystal Growth 281, 91 (2005).

[26] Dwiliński, R., Doradziński, R., Garczyński, J., Sierzputowski, L. P., Puchalski, A., Kanbara, Y., Yagi, K., Minakuchi, H., and Hayashi, H., J. Crystal Growth 311, 3015 (2009).

[27] Saarinen, K., Hautojärvi, P., and Corbel, C., in Identification of Defects in Semiconductors, edited by M. Stavola, Academic Press, New York, 209 - 295 (1998).

[28] Reurings, F., Tuomisto, F., Egger, W., Löwe, B., Ravelli, L., Sojak, S., Liliental-Weber, Z., Jones, R. E., Yu, K. M., Walukiewicz, W., and Schaff, W. J., Phys. Status Solidi A 207, 1087 (2010).

[29] Tuomisto, F., and Makkonen, I., submitted to Rev. Mod. Phys.

[30] Tuomisto, F., Ranki, V., Look, D. C., and Farlow, G. C., Phys. Rev. B 72, 165207 (2007).

[31] Puska, M. J., Corbel, C., and Nieminen, R. M., Phys. Rev. B 41, 9980 (1990).

[32] Look, D. C., Farlow, G. C., Drevinsky, P. J., Bliss, D. F., and Sizelove, J. R., Appl. Phys. Lett. 83, 3525 (2003).

[33] Oila, J., Kemppinen, A., Laakso, A., Saarinen, K., Egger, W., Liszkay, L., Sperr, P., Lu, H., and Schaff, W. J., Appl. Phys. Lett. 84, 1486 (2004).

[34] Rauch, C., Reurings, F., Tuomisto, F., Veal, T. D., McConville, C. F., Lu, H., Schaff, W. J., Gallinat, C. S., Koblmüller, G., Speck, J. S., Egger, W., Löwe, B., Ravelli, L., and Sojak, S., Phys. Status Solidi (a) 207, 1083 (2010).

[35] Pelli, A., Saarinen, K., Tuomisto, F., Ruffenach, S., and Briot, O., Appl. Phys. Lett. 89, 011911 (2006).

[36] Rauch, C., Tuna, Ö., Giesen, C., Heuken, M., and Tuomisto, F., Phys. Status Solidi (a) 209, 87 (2012).

[37] Reurings, F., Tuomisto, F., Gallinat, C. S., Koblmüller, G., and Speck, J. S., Appl. Phys. Lett. 97, 251907 (2010).

[38] Tuomisto, F., Pelli, A., Yu, K. M., Walukiewicz, W., and Schaff, W. J., Phys. Rev. B 75, 193201 (2007).

[39] Reurings, F., Rauch, C., Tuomisto, F., Jones, R. E., Yu, K. M., Walukiewicz, W., Lu, H., and Schaff, W. J., Phys. Rev. B 82, 153202 (2010).

[40] Tuomisto, F., Mäki, J.-M., Rauch, C., and Makkonen, I., J. Crystal Growth 350, 95 (2012).

[41] Tuomisto, F., Saarinen, K., Bockowski, M., Suski, T., Paskova, T., and Monemar, B., J. Appl. Phys. 99, 066105 (2006). 
[42] Tuomisto, F., Saarinen, K., Lucznik, B., Grzegory, I., Teisseyre, H., Suski, T., Porowski, S., Hageman, P. R., and Likonen, J., Appl. Phys. Lett. 86, 031915 (2005).

[43] Paskova, T., Hommel, D., Paskov, P. P., Darakchieva, V., Monemar, B., Bockowski, M., Suski, T., Grzegory, I., Tuomisto, F., Saarinen, K., Ashkenov, N., and Schubert, M., Appl. Phys. Lett. 88, 141909 (2006).

[44] Rummukainen, M., Oila, J., Laakso, A., Saarinen, K., Ptak, A. J., and Myers, T. H., Appl. Phys. Lett. 84, 4887 (2004).

[45] Uedono, A., Chichibu, S. F., Higashiwaki, M., Matsui, T., Ohdaira, T., and Suzuki, R., J. Appl. Phys. 97, 043514 (2005).

[46] Uedono, A., Ishibashi, S., Ohdaira, T., and Suzuki, R., J. Crystal Growth 311, 3075 (2009).

[47] Uedono, A., Ishibashi, S., Watanabe, T., Wang, X. Q., Liu, S. T., Chen, G., Sang, L. W., Sumiya, M., and Shen, B., J. Appl. Phys. 112, 014507 (2012).

[48] Mattila, T., and Nieminen, R. M., Phys. Rev. B 55, 9571 (1997).

[49] Koyama, T., Sugawara, M., Hoshi, T., Uedono, A., Kaeding, J. F., Sharma, R., Nakamura, S., and Chichibu, S. F., Appl. Phys. Lett. 90, 241914 (2007).

[50] Uedono, A., Ishibashi, S., Keller, S., Moe, C., Cantu, P., Kantona, T. M., Kamber, D. S., Wu, Y., Letts, E., Newman, S. A., Nakamura, S., Speck, J. S., Mishra, U. K., Denbaars, S. P., Onuma, T., and Chichibu, S. F., J. Appl. Phys. 105, 054501 (2009).

[51] Nykänen, H., Suihkonen, S., Kilanski, L., Sopanen, M., and Tuomisto, F., Appl. Phys. Lett. 100, 122105 (2012).

[52] Van de Walle, C. G., and Neugebauer, J., J. Appl. Phys. 95, 3851 (2004).

[53] Armitage, R., Hong, W., Yang, Q., Feick, H., Gebauer, J., Weber, E. R., Hautakangas, S., and Saarinen, K., Appl. Phys. Lett. 82, 3457 (2003).

[54] Reurings, F., and Tuomisto, F., Proc. SPIE vol. 6473, 64730M (2007).

[55] Lyons, J. L., Janotti, A., and Van de Walle, C., Appl. Phys. Lett. 97, 152108 (2010). 